\title{
Smart Cities Development During and Post COVID-19 Pandemic - A Predictive Analysis
}

\author{
Dipak S. Gade ${ }^{1} \&$ P. S. Aithal ${ }^{2}$ \\ ${ }^{1}$ Post Doctoral Research Scholar, Department of Computer Science and Engineering, \\ Srinivas University, Mangalore, India \\ ORCID ID: 0000-0002-0962-0375, Email: dipak.pdf@ srinivasuniversity.edu.in \\ ${ }^{2}$ Vice Chancellor, Srinivas University, Mangalore, India \\ ORCID ID: 0000-0002-4691-8736, E-mail: psaithal@ gmail.com
}

Area/Section: Business Management.

Type of the Paper: Review Based Analysis.

Type of Review: Peer Reviewed as per $|\mathrm{C}| \mathrm{O}|\mathrm{P}| \mathrm{E} \mid$ guidance.

Indexed in: OpenAIRE.

DOI: https://doi.org/10.5281/zenodo.4903338

Google Scholar Citation: IJMTS

\section{How to Cite this Paper:}

Gade, Dipak S., \& Aithal, P. S., (2021). Smart Cities Development During and Post COVID-19 Pandemic - A Predictive Analysis. International Journal of Management,

Technology, and Social Sciences (IJMTS), 6(1), 189-202. DOI: https://doi.org/10.5281/zenodo.4903338.

International Journal of Management, Technology, and Social Sciences (IJMTS)

A Refereed International Journal of Srinivas University, India.

CrossRef DOI: https://doi.org/10.47992/IJMTS.2581.6012.0140

(C) With Author.

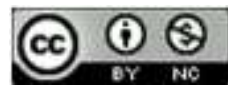

This work is licensed under a Creative Commons Attribution-Non-Commercial 4.0 International License subject to proper citation to the publication source of the work.

Disclaimer: The scholarly papers as reviewed and published by the Srinivas Publications (S.P.), India are the views and opinions of their respective authors and are not the views or opinions of the SP. The SP disclaims of any harm or loss caused due to the published content to any party. 


\title{
Smart Cities Development During and Post COVID-19 Pandemic - A Predictive Analysis
}

\author{
Dipak S. Gade' \& P. S. Aithal ${ }^{2}$ \\ ${ }^{1}$ Post Doctoral Research Scholar, Department of Computer Science and Engineering, \\ Srinivas University, Mangalore, India \\ ORCID ID: 0000-0002-0962-0375, Email: dipak.pdf@ srinivasuniversity.edu.in \\ ${ }^{2}$ Vice Chancellor, Srinivas University, Mangalore, India \\ ORCID ID: 0000-0002-4691-8736, E-mail: psaithal@ gmail.com
}

\begin{abstract}
Purpose: The Smart Cities due to their important role in infrastructure building activities and offering smart services to their residents in living an enjoyable life are always in the limelight and discussions. The current COVID-19 pandemic has however changed the situation, and has forced us to rethink the way we operate, carry out day to day activities and services. COVID19 pandemic has changed the normal routine life to a significant extent, damaged the economies of many countries, shifted our business priorities, and so on. In such situations, how can Smart Cities remain unaffected due to COVID-19? This paper has analysed and discussed in detail the impact of the COVID-19 pandemic on Smart Cities operations and development and also, how this impact can be measured. It has described in detail how Smart Cities has changed their priorities and how they are more focusing on building Smart Healthcare facilities, Smart Isolation Wards, Smart Medicare facilities, services related to Telemedicine, Virtual Doctor, dedicated COVID-19 Command and Control Centres and so on. The paper has also highlighted the post COVID-19 Pandemic era for Smart Cities development and operations. Finally, the paper has concluded that Smart Cities development during and post COVID-19 Pandemic has witnessed a short obstacle in its growth journey, Smart Cities are definitely going to win the war against COVID-19 and will become Smarter in the future to tackle such pandemics.
\end{abstract}

Design/Methodology/Approach: This research paper made use of available secondary data in research journal papers, online books, white papers, and dedicated websites on the research subject area to analyze the impact of COVID-19 Pandemic on Smart Cities Development and Operations.

Findings/Result: Due to COVID-19 Pandemic, it is observed that many sectors growth slow down due to budget cut and financial constraints, however, certain sectors such as Medical Infrastructure, Insurance, and eCommerce have seen booms, this has made Smart Cities to have a strong focus on certain Smart Services related to Medical facilities, IT infrastructure to facilitate contactless transactions, Telemedicine Service, Smart Isolation Wards, etc. whereas services with respect to entertainment parks, tourism, etc. slowed down due to less priority and budget constraints.

Originality/Value: Based on the available secondary data, this research has identified the impact of COVID-19 on ongoing Smart Cities development and also how its priorities and focus got shifted to build up certain services and infrastructure. The paper has also highlighted post COVID-19, how Smart Cities development, operations, and maintenance activities will be affected.

Paper Type: Secondary data-based Research

Keywords: Smart City, IoT, Digital Twin, Artificial Intelligence, Data Analytics, COVID-19

1. INTRODUCTION :

The COVID-19 pandemic left unprecedented impacts not only on individuals but also on the major segments of societies including industries, education, business and trades, governments, environments 
and almost all the activities of the mankind as a whole. In the beginning of January 2020, no one had any idea that a small outbreak of COVID-19 in Wuhan, capital of Hubei Province of China, which was initially considered as China specific outbreak, will go and spread widely to the whole world with in few months of time and will cause millions of people hospitalization and killings worldwide. By this time, it is also clear that this pandemic is not going to go away soon and with limited stock of reliable vaccine for COVID-19 as of now, mankind needs to prepare to stay with COVID-19 for longer duration. No doubt that this bitter truth has forced us to change our day to day activities, the way we were doing business, office activities, travels, transactions, meetings and so on. The way we were living before COVID-19 phase is not going to return soon and quite possible that COVID-19 has forced us to permanently change some of our routine activities. We are currently undergoing industry 4.0 revolution and the fact that this pandemic has happened in the middle of our digital revolution journey, is not gone unnoticed. The most advanced countries such as USA, UK, Russia, France, Germany, Spain etc. which are forefront in technology upgradation, innovation, modern facilities, and infrastructure are currently worst affected by COVID-19 pandemic.

Smart Cities due to its smart infrastructure and well governance are always ready and prepared for such kind of disaster be it god made or man-made and can comparatively do a better job in facilitating better pre and post medical facilities and treatment [1]. Globally, almost all the countries have put forward medical treatment and COVID-19 safety related activities at highest priority, keeping and provisioning maximum budget for it. Obviously for other activities budget is either slashed or no more budget is available. This has made other domains and industries greatly impacted but in COVID-19 phase, in reality, this has boosted development of Smart Cities with better medical infrastructure and facilities. It is estimated by United Nations that $68 \%$ of the world's population will live in urban areas by 2050 , and more and more people will migrate to Smart Cities in coming period in hope of getting better livelihood. Let us see in detail how Smart Cities are fighting against COVID -19.

\section{PROBLEM STATEMENT :}

COVID-19 pandemic has drastically affected our businesses and day to day activities. It has also impacted various business sectors including Smart Cities. We felt that there is a need to determine how Smart Cities development and operation activities are coping up with the current pandemic situation. Is there any way to identify how Smart Cities development and operations are affected due to COVID-19 pandemic and how we can quantify it, what tools are there to evaluate such impact? Such data will definitely help to further boost Smart Cities development, operations, and maintenance activities during and post COVID-19 pandemic.

\section{RESEARCH OBJECTIVES :}

COVID-19 pandemic impact on Smart Cities development and operations is very vast and complex subject. It is not possible to completely cover each and every aspect related to COVID-19 pandemic impact on Smart Cities. However, with the available time constraints, limited tools and limited available literature, the research is carried out keeping in mind following broad objectives

- Study the existing available research papers, white papers, online blogs, research reports from SMEs and Government Organisations and dedicated website on the research subject area.

- Identify the important services of Smart Cities which are got heavily impacted (either positively or negatively) due to COVID-19 Pandemic.

- What current tools and technologies are used to measure and quantify COVID-19 pandemic impact on Smart Cities Development, Operations and Maintenance related activities.

- Analysis and discussion on post COVID-19 era for Smart Cities development and operations.

\section{METHODOLOGY :}

This research is entirely based on study and analysis of existing literature available on COVID-19 pandemic effect on Smart Cities development, operation, and maintenance. It is observed that not many research papers are available on this subject and hence we mainly focused on study of white papers, conference papers, online books, blogs, and dedicated websites for tackling COVID-19 pandemic and Smart Cities. Specific keywords and phrases such as "Smart City", "COVID-19" "COVID-19 impact" "COVID-19 effect on Smart Cities" "Smart Cities fight with COVID-19" "Smart City and COVID-19", were used while identifying relevant online literature. The collected literature was then analysed 
considering the data provided, quantified information, tools and technologies discussed and proposed, finance related data, notes on affected geographies, patients related data, etc. to identify challenges faced by Smart Cities to tackle COVID-19 pandemic and its impact on their services considering operating cost, manpower and required infrastructure for dealing with COVID-19 Pandemic. We also went through the existing Interviews of Subject Matter Experts, Researchers, and Industry Professionals to understand their stand on how Smart Cities will emerge post COVID-19 era.

\section{RELATED RESEARCH WORKS :}

Pandemic like COVID-19 is not new on the earth. The world has experienced similar situations such as the Marseille plague in 1720, cholera pandemics around 1817 and 1823, Spanish flu Pandemic around 1918 and 1919, Asian Flu in 1957, Hong Kong flue in 1968, and the most recent Swine Flu in 2009 [2]. Coronavirus Disease 19 (COVID-19), caused by Severe Acute Respiratory Syndrome Coronavirus 2 (SARS-CoV-2), and the first case of COVID-19 was detected in December 2019 in China (World Health Organization, 2020). The commonly reported symptoms of the virus include fever, persistent cough, fatigue, and loss of taste or smell [3]. In the case of COVID-19, the source of infection is mainly due to the infected patients. According to the clinical evidence of previous respiratory syndromes, respiratory droplets and personal contact are found as primary transmission methods [4]. COVID-19 pandemic has affected everyone however older people, socially and economically disadvantaged populations are at higher risks of becoming infected. Lorenz Seidlein, Graham Alabaster, et al, in their paper have highlighted that crowding is also one of the important factors in COVID-19 infection and spread [5]. Authors feel that crowding is difficult to quantify and address, however, in many ways, it is linked to socioeconomic status and can be defined in terms of floor space/person instead of population density. Wealthy and well-off people can afford more floor space and can avoid public transportation however, the low-income group population doesn't have such kind of freedom and hence prone to get infected due to COVID-19.

For the first time in 21st Century, the world witnessed the most devastating impact due to pandemic like COVID-19 which is still ongoing in the year 2021 and unfortunately, we were not ready, not prepared for it. Second thing, even though we are in the 4th stage of the industrial revolution and technologically much more advanced as compare to our 20th-century era, still it seems we miserably failed to predict the adverse impact of COVID-19 pandemic across the globe. Many scientists, researchers, and professors during COVID-19 period started working on remedies to tackle the situation to the best possible extent either by accelerating the research in identifying COVID-19 detection tests and to reduce the time it takes to produce results, COVID-19 vaccines trials, and the emergency measures to prevent COVID-19 waves in future. Nenad Petrovic, Vlado Dimovski, et al, in their paper stated that to deal with COVID-19 pandemic situation in Smart Cities, more innovative solutions and sophisticated methods are needed. They highlighted the need for data-driven applications as an important tool to enable the quality of life and well-being of citizens [6]. They suggested the use of mobile apps developed using AppSheet and Google Apps Script technologies and demonstrated how these Apps can be used to limit the spread of COVID-19 and provide assistance to infected people. The authors also stated an example of Smart Cities Seoul and Singapore, which were the first Smart Cities to develop technological solutions based on data-driven applications to help their citizens during COVID-19. Along similar lines, Ibrahim Hashem, Absalom Ezugwu, et al, proposed a machine learning-based framework in their research paper to curtail the spread of COVID-19 epidemic specifically in Smart Cities [7]. The authors stated that the novel mathematical model can generate the results based on the collected and analysed data with respect to COVID-19 pandemic, using a machine learning algorithm, and the results can be extensively used to prevent the spread of COVID-19, in forecasting future epidemic, diagnose cases, effective contact tracings, monitor COVID-19 patients, track COVID-19 vaccine development and so many such activities and provide a better understanding of the virus in smart cities.

Linda Hantrais, Paul Allin, et al, in their research paper has successfully demonstrated how the COVID19 Pandemic has accelerated the growth in worst impacted business areas by making them adopting digital transformation techniques and accelerating their operation through online transaction, online meeting, social connect over network, online business meetings, online data collection and analysis and so on [8]. Such businesses obviously start showing growth by improved productivity. But such activities also demanded to pump in more investment in digital infrastructure. 
To avoid the rapid spread of COVID-19 infections, governments of many countries extensively used lockdown as the only option. Mikiharu Arimura, Tran Vinh Ha, et al, in their research paper has shown that how the COVID-19 infections are greatly affected the densely populated areas of the Sapporo City of Japan before and during the lockdown [9]. Their study reveals how a rapid transit system involves a higher risk of spreading COVID-19 due to the close contact with high passenger density inside the cab, it is mainly because public moves to private cab travel during lockdown when public transportation system was not available. Though lockdown severely affected the economy and financial conditions across the globe, it also helped in many ways specifically with respect to the environment. Recent studies and conducted surveys revealed that lockdown extensively helped to improve the air quality specifically in Smart Cities and urban areas where more anthropogenic activities are present [10]. Some studies conducted worldwide indicated remarkable declines of AQI were observed in $\mathrm{NO} 2(44 \%$ to $13 \%$ ), ozone (20\% to $2 \%$ ) and PM2.5 (28\% to 10\%) during the first two weeks of the lockdown in 27 countries [11].

According to Bo Li, Yo Peng, et al, COVID-19 directly impacted populated and commercially prospered regions like Huangzhou, China. Their study reveals the relationship between built environment attributes and confirmed COVID-19 cluster size. They have stated that the well-connected and steady supply of medical service is associated with high commercial prosperity at the community level and it directly, indirectly, and positively affects the COVID-19 cluster size. Ayyoob Sharifi and Amir Reza Khavarian-Garmsi in their review paper tried to identify the most impacted urban sectors due to COVID-19, which requires better preparedness to deal with similar pandemics in the future [12]. The authors feel that COVID-19 has fundamentally altered the way the cities are going to be managed and governed in the future. They also claim that the actions being taken in coming years to tackle COVID-19 will determine how the cities will be developed and managed to post COVID-19 era, in a more sustainable manner.

Chunwen Xu, Xillian Luo, et al, in their paper have highlighted the future of Smart Cities post COVID19, and they also provided useful suggestions for building future healthy Smart Cities. They stressed the need of establishing a national popularization mechanism for health science, improving the emergency security mechanism, and establishing a multi-industry coordination mechanism [13]. The authors also strongly suggested using Artificial Intelligence-based applications to deal with various services such as logistics supply chain, traffic management, infection detection, vaccination, etc. for modern data-based Smart Cities. Klaus R. Kunzmann, in his research paper elaborated on the likely impact COVID-19, will have on Smart City development and its policies to apply digital technologies in urban development [14]. He provided 10 narratives related to returning to normal life post CPOVID19, the revival of Car Mobility, digital culture, and entertainment, the demise of non-digital creative industries, nearby or home tourism, public sector boostings, etc., and anticipated that Smart City development will experience a boost after COVID-19.

\section{COVID-19 IMPACT ON SMART CITIES DEVELOPMENT :}

COVID-19 has slowed down the overall growth for many countries due to forced lockdown and increased expenses to tackle the pandemic situation. Also, in efforts to provide relief to citizens from mounting medical expenses, many governments have also provided a lot of concessions and relaxation in taxation. However, despite reduced workforce and decreased tax revenues, globally, many governments and NGOs, WHO and other global private organizations are deploying advanced technology-based solutions such as IoT, Big Data, Digital Twins, Data Analytics, Cloud Computing, Cyber Security, etc. to help combat the worst-case impact due to COVID-19 pandemic by monitoring the health, safety, and living standard of the citizens [15]. Though there will not be much budget to undertake many development activities, which can also cause to slow down Smart Cities development on some of the fronts, it is sure that technology deployment at larger scale to combat war against COVID-19 pandemic, and larger investment in technology can definitely boost health, hygiene and medical infrastructure related development activities in Smart Cities. With the upcoming investment, it is also expected that Smart City technology providers can witness a steady adoption of solutions for various other areas such as smart buildings, smart utilities, smart transportation, and smart citizen services.

According to US based leading technology research and advisory firm ARC Advisory Group following are some of the selected examples which prove that additional investment on technology front by some 
the leading nations are boosting the Smart Cities development around the globe during COVID-19 phase.

(1) Smart City investment around USA and Canada

US and Canada have many large Smart Cities and municipalities in North America are very diverse in size as compare to other parts of world. In this region, a huge number of medium sizes and smaller cities are investing in smart city projects heavily. Refer Figure 1 which is representing the top 3 focus areas in Smart City development in North America.

(2) China boost Smart City Investments and Technology Initiatives

China's "new infrastructure initiative" program got widespread attention and priority in the wake of COVID-19, using increased investment in smart city technologies to promote innovation and boost the economy while tackling COVID-19 posed threats and challenges. China has announced that it is going to significantly increase investments in high-speed internet based on 5G, data centres, smart grids, and other smart city-related areas. Aggregating sources of data across cities has already been started as a major part of the initiative and shall support significant growth in smart city platforms.

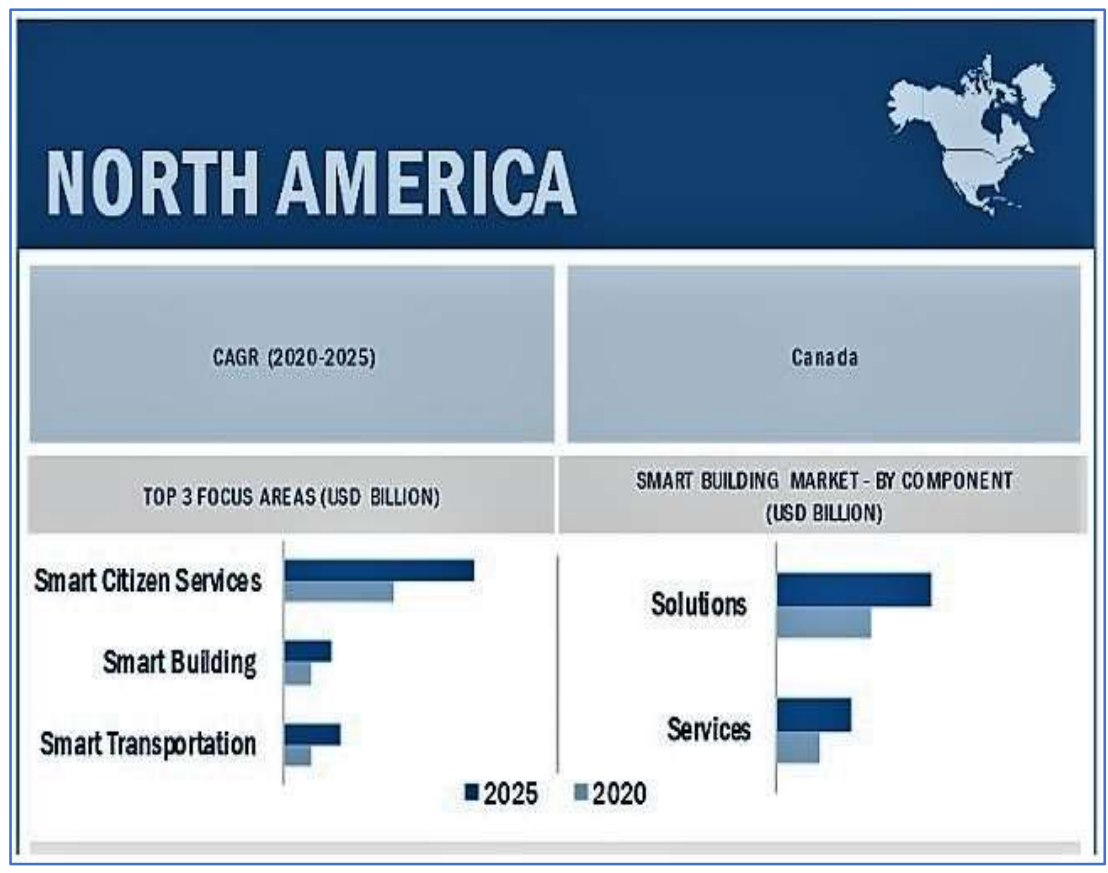

Fig. 1: Smart City Focus Areas in North America (Source: MarketsandMarkets ${ }^{\mathrm{TM}}$ Smart Cities Report)

(3) Singapore Increases Technology Investment by 30 Percent

Singapore is one of the early adopters of Smart City Technologies. Singapore government announced in June 2020 that to better fight COVID-19 pandemic, it is going to increase its investment in information technology by 30 percent. The Singapore Government Technology Agency (GovTech) announced that it would spend around $\$ 3.5$ billion in 2020, up from $\$ 2.7$ billion in FY 2019.

(4) Investment into Data Management and Analysis Tools by New Orleans and other US Cities Many US cities have established data processing centres based on new technology tools to track key trends with respect to COVID-19 pandemic and powerful dashboards representing data with respect to new infections, fatalities, recoveries, recovery rate, etc. with geographical data to determine which areas require more attention. For example, the city of New Orleans in Louisiana has setup dashboard by using tools like Power BI to help with data trends for COVID-19. 


\section{(5) UAE invested in AI based system}

In United Arab Emirates, the impact of smart city technologies to control the virus' spread can also be seen, where the UAE government is using Artificial Intelligence ( AI) based Smart System to ensure that social distancing and lockdown related guidelines are followed by its citizens. The system uses data captured by Smart Helmets installed with Thermal Cameras, which helps the local police to detect COVID-19 suspects from safe distance. The System also helps the administration by identifying people who are roaming on roads with their vehicles without having valid pass. This Information is collected by system by reading the number plates of vehicles and matching the details with those vehicles who have been issued pass to occasional travel on justified medically or emergency situation ground.

\section{(6) India invested in Smart Cities Infrastructure}

In India as well, Indian government has taken a lot of initiatives in boosting investment in the Smart Cities infrastructure and medical infrastructure facilities development, which has kept the government agencies ahead in curbing the spread of deadly Corona virus. The Indian Medical Council, with the new guidelines issued by the ministry of health and family welfare and as per recommendations from NITI Aayog, has allowed remote delivery of Medical Services during the lockdown period. These new guidelines allow doctors to recommend prescriptions to patients based on textual, telephonic, and video conferencing and also through WhatsApp Chat, Emails, and messaging services. With these new norms in place, people can consult with the doctors and medical specialists over mobile through video call or normal audio call without needing to go out for in person meeting and thus effectively reducing risk of deadly corona virus spread. The Mobile App "Aarogya Setu" is developed by the Government of India for combined fight against COVID19 by connecting essential health services with the people of India. Refer figure 2 which is showing the GUI provided by Aarogya Setu App.

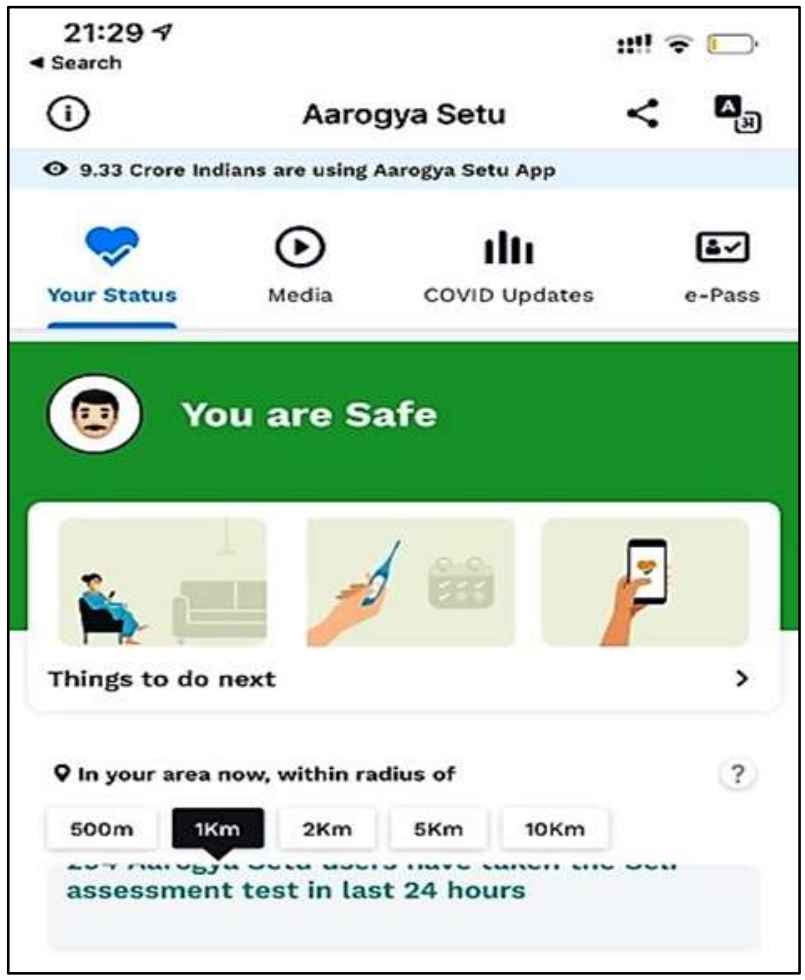

Fig. 2: Aarogya Setu App

(Source : Aarogya Setu App, Government of India)

The "Aarogya Setu" app is aimed at reaching out the app users proactively by informing and alerting them about risky areas, providing them dashboard with recommendations about COVID-19 infections chances, facility to book online vaccinations slots, alerting them about nearby COVID-19 Infections 
and information about best practices and relevant advisories pertaining to the containment of COVID19. It should be noted that Aarogya Setu App is available in 10+ local languages and became the world's fastest app to reach 50 million downloads within two weeks of its launch.

\section{SMART CITIES INITIATIVES IN INDIA TO TACKLE COVID-19 :}

Indian government has also taken a lot of initiatives in deployment of advanced technology-based tools across country and boosting infrastructure development across various Smart Cities to ensure effective handling and reducing the impact of COVD-19 pandemic situation. As part of the Indian governmentfunded Smart Cities Mission, 45 cities have established and make operational COVID-19 Integrated Command and Control Centers (ICCC). Refer figure 3 which has shown the block diagram of typical ICCC used in Smart Cities. These centers were established to serve as quasi-war rooms to manage contact tracing activities, monitor and effectively handle the lockdown state and to deal with emergency situations arising out of COVID-19 pandemic [16-17]. Some of the selected case examples of such Smart Cities in India are as follows:

\section{(1) Mangaluru Smart City}

Under Mangaluru Smart City Project, Karnataka State has setup a dedicated call centre as telemedicine facility for monitoring and advising the citizens under self-quarantine. Under this project a Command and Control Centre is also established along with dedicated professionals from Mangaluru Corporation, Police and Doctors.

\section{(2) Bhopal Smart City}

Under Bhopal Smart City Project, an Integrated Command and Control Centre is established and operated by state of Madhya Pradesh. This centre is operated as a helpline and used for telecounselling for COVID-19 Patients with the help of trained station staff and medical professionals. The centre's helpline is integrated with 104 service and toll-free numbers of ICCC.

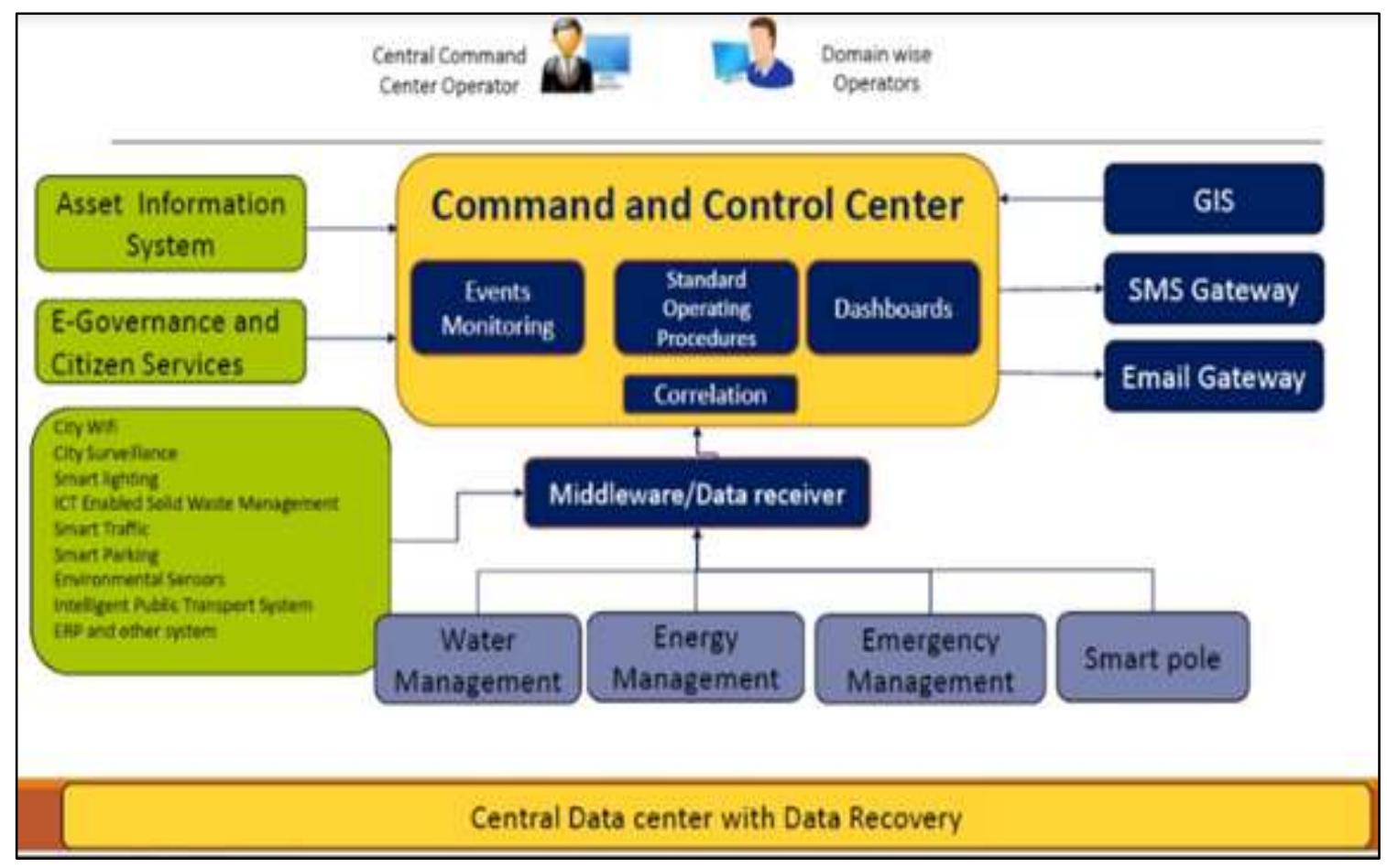

Fig. 3: Typical ICCC for Smart City

(Source : Smartnet Library, Government of India)

(3) Kanpur Smart City 
Under Kanpur Smart City Project, state of Uttar Pradesh has setup dedicated ICCC specifically to help the citizens to deal with COVID-19 Pandemic by providing telemedicine facilities through toll free telephone help lines as well as through video conferencing.

\section{(4) Nagpur Smart City}

In Maharashtra State, Nagpur Municipal Corporation (NMC) under Nagpur Smart City Project has launched a Coronavirus Mobile App to help citizens to identify patients with corona virus infection related symptoms. The App is very simple and user friendly where the citizens have to fill the online information form related to their symptoms and the app detects the possibility of Corona Virus infection to the citizens. In case of confirm identified symptoms related to COVID-19, the app automatically notifies to the team of NMC doctors for further recommended actions including admitting the patient to COVID-19 Cell or an isolation ward to undergo necessary treatment.

\section{(5) Varanasi Smart City}

In Uttar Pradesh State, the established integrated command and control centre to deal with COVID19 pandemic, a GIS (Geographical Information System) based dashboard is effectively uses to identify lockdown violations, quarantine leakages, essential commodities delivery and facilitate emergency alert response.

According to MHUA (Ministry of Housing and Urban Affairs) India, the new initiatives by various Smart Cities across India has helped the district administrations in not just tracking suspected cases of Corona virus infected people but also monitoring the successful implementation of months long nationwide lockdown.

\section{HOW COVID-19 AFFECTED 'SMART CITY' PRIORITIES :}

Before COVID-19 development and construction of smart facilities in Smart Cities was on higher priority. The objective was to offer a better lifestyle to all its citizens at the earliest. Offering Smart Medical facilities was also one of the objectives, but it was not on highest priority. As stated earlier, due to concessions offered in taxation and lower revenue collection, the budget is either not available or slashed for other development activities. Also, due to prolonged lockdown, it became difficult to get ready workforce. This has definitely impacted Smart Cities development as well. Apart from COVID19 related investments in Technology and relevant Medical Infrastructure, development for other projects in Smart Cities are significantly impacted and delayed, such projects are new bridge constructions, new high ways, futuristic skylines, futuristic restaurants, and shopping malls, modern sports facilities, smart-city led lighting system, new educational institutions, smart traffic management related Projects, projects related to nightlife and leisure activities, new Parks and side-walks constructions etc. Obviously, all these projects went on backfoot due to COVID-19 pandemic, and medical infrastructure and relevant technology-related projects got higher priority. In May 2020, Financial Express has reported that due to COVID-19 pandemic, an imposed prolonged lockdown across India, has halted Smart City projects worth close to Rs 1 lakh crore, rendering thousands of workers jobless and causing large-scale damage of building materials. City Monitor from Mediagroup.com has reported that Sidewalk Labs abandoned its Waterfront Toronto project in May 2020 citing the reason for the economic pressures of the global pandemic. There are so many such examples of popular projects which were considered as a top priority before COVID-19 and subsequently got either delayed, scaled-down, or abandoned in COVID-19 phase. It is sure that the pandemic has highlighted the need for better medical infrastructure, hygiene, and better environment accelerated digital city planning and greater communication with citizens for massive population levels to be sustainable. Also, with change in priorities, Smart City development may see an investment shortfall in near future for some of the development projects and can witness a massive jump in smart medical facilities development [18-23].

\section{MEASUREMENT OF COVID-19 IMPACT ON SMART CITIES :}

It should be noted that till all the population is not vaccinated, social distancing and lockdown restrictions found as an effective way to control the spread of deadly Corona Virus infections. However, after seeing worldwide economic recession due to prolonged lockdown in many countries, people have 
realized the fact that continuous lockdown cannot be the effective solution to curb the spread of the deadly COVID-19 pandemic. Recent announcements from some of the major countries including the USA and India to lift the lockdown restrictions and opening of business activities, makes the medical institutions around the world think that this can cause to sudden increase the spread of the COVID-19 pandemic and can be very well considered as the second wave of Corona infections. Under such situations it is always better to have some ideas that how much impact will be there by gradually lifting the lockdown in selected areas.

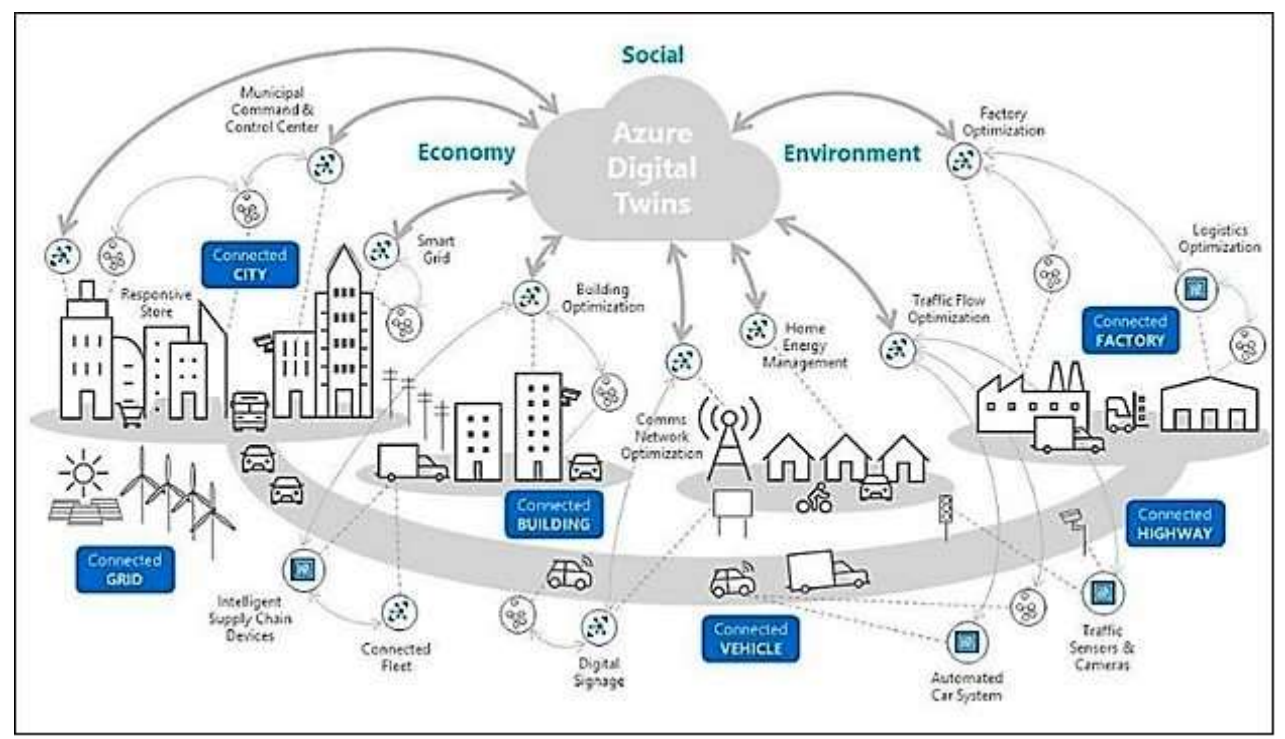

Fig. 4: Azure Digital Twins for Smart City (Source: Microsoft Azure Blog on Digital Twins)

Experts have claimed that to measure such impact on Smart City, Digital Twin of Smart Cities can help. Digital Twin is basically the virtual model of the system which can exhibit almost the same behavior when subjected to specific simulated situations like a real system which will undergo the same real situations and can behave in the same manner. This technology is possible with the help of advanced IoT sensors which are used to detect certain input conditions and with the help of augmented and virtual reality helps to build the digital model of the real system under the test and observations. Refer to figure 4, it has shown the block diagram of Azure based Digital Twin of a typical Smart City. Digital Twin of Smart City will offer great help for the governments and administration bodies to quickly assess the emergency situation and its impact on Smart City operation well ahead of time by checking the behavior with its Twin through simulated conditions. This can help Government to better analyze the situation and in determining the safety and economic implications while taking critical decisions such as relaxing lockdown or while imposing fresh lockdown. Also, it will greatly improve the government's ability while making new policies for Smart Cities. Virginia University's Biocomplexity Institute has developed a Digital Twin Simulation Platform for Smart City that could help local government authorities to analyze and better anticipate the COVID-19 spread, which can also help the local government in understanding the impact of Corona virus-related policies. It should be noted that earlier Digital Twins for Smart Cities were used to improve disaster management mostly, however in the COVID-19 crisis phase, Digital Twins of Smart Cities are used for better analysis and management of COVID-19 pandemic.

\section{CAN SMART CITIES WIN THE FIGHT AGAINST COVID-19 :}

COVID-19 pandemic has literally paralyzed the worldwide economy by forcing prolonged lockdown in many countries and by imposing stringent restrictions while performing day-to-day essential activities. COVID-19 devastating impact on governments and civil societies has made a deep scar and wound which will take a long time for healing. Global scientists are making their best efforts to have clinically proven and reliable vaccine for COVID-19 should be available at the earliest, but till now 
most of the COVID-19 Vaccines are in trial stage and not found 100\% effective. Having said all this, does it mean that mankind is going to lose hope? The answer is definitely NO. Smart Cities with Smart infrastructure are in fact helping the governments in the best fight with the COVID-19 pandemic [2429]. Worldwide developed, more developed and developing countries are effectively using sophisticated technology-enabled tools of Smart City such as e-governance, telemedicine, econsultation, GIS-enabled monitoring system, Mobile App enabled alert and notification system augmented and virtual reality-based digital twins to assess and analyze COVID-19 pandemic effect. Smart Cities have also emphasized the importance of the digital transformation in many forms of work such as online virtual education, remote work and executions, teleconsultations, online trading, ecommerce platform, and many such environmentally friendly practices which have resulted into drastic reduction in the carbon footprint, noise pollution, traffic, and its congestions. With so many tools and technologies in hand, Smart Cities are found as an effective weapon to many countries governments to fight against the deadly coronavirus pandemic. It should also be noted that the investments made in relevant tools and technologies related to Smart City medical infrastructure development can be used in other urban cities and towns in countries where Smart Cities are not set up and built as of now. The results that we have so far in curbing the spread of COVID-19 due to Smart City technologies, are making non-developed and or underdeveloped countries as well to initiate Smart Cities setting up and building. Smart Cities have greatly enhanced the concept of public-private partnership (PPP), and the collaboration between the City administration authorities including municipalities and the innovation ecosystem in fighting against the deadly COVID-19 pandemic. No doubt that such a framework is very effective in bridging capability gaps and needs and thereby it is sure that in the coming days, Smart Cities shall definitely win the war against COVID-19.

\section{SMART CITIES DEVELOPMENT AND OPERATIONS POST COVID-19 :}

It is true that due to COVID-19, we need to now make some of the practices as part of life on a continuous basis such as social distancing, hygiene maintains, washing hands periodically in a day, wearing the mask, readiness for medical emergencies, and so on. Definitely, this also has impacted the way Smart Cities are developed, operated, and maintained. It is widely accepted that the COVID-19 pandemic has made us rethink and reorder the economic and governance landscape across the globe, it has also necessitated reprioritization of many of the things and now the focus has directed in specific sectors and areas such as medical, disaster management, remote operations, virtualization, eCommerce, online transactions, cybersecurity, etc. Thus, it is clear that post COVID-19 environment has shifted focus and priorities and brought more emphasis on certain aspects such as accelerating medical and healthcare infrastructures, efficient deployment of mass health services, health surveillance, health insurance, and remote Medicare services. For Smart Cities, the new mantra has emerged and that is to accelerate health services at larger scale using the latest tools and technologies. Enable telemedicine helpline, facilitate remote operations, allow contactless transactions, and keep the bandwidth of the service free to tackle emergency crises. "Many of the changed requirements and behaviours by the pandemic such as touchless, safety-oriented, community resilience, etc. will persist even when the crisis wanes," according to Gartner.

The social and economic disruption due to COVID-19 pandemic situation has impacted even the tool and technologies to a greater extent. For example, it is now obvious that IoT sensors are in more demand than ever before, in operating smart infrastructure and Smart buildings, due to their facilitation of enabling the remote data-driven operation to present true monitoring and operational scenarios. According to Gartner Report-Market Trends: 5 Smart City IoT Deployment Trends to Drive Innovation Opportunities, post-COVID-19, IoT shall play an important role in smart cities due to the demanding focus on safe and secure connected building, smart infrastructure for city operation, such as road toll collection through contactless technology, city asset tracking, smart traffic management, smart metering and assisted living, outdoor surveillance. The Gartner Report also noted in post-COVID-19 Smart Cities, technologies such as Artificial intelligence, IoT along with digital twins, can facilitate predictive modelling techniques which can enable Smart Cities to determine safety, security and effective implementation of various policies useful to deal with any pandemic situations.

It should be noted that during COVID-19 some of the Smart Cities (such as Taipei, Seoul, Hongkong, Singapore) performed excellently over others in dealing with the pandemic situation quickly and effectively not because they already had experience of dealing with similar virus pandemic situations 
like Severe Acute Respiratory Syndrome (SARS), but due to their effective and immediate actions in the deployment of smart technologies which greatly assisted them to tackle crises at the initial stage itself.

Post COVID-19 can also possibly make some of today's "nice to have" services as essential services such as digital transformation, smart health monitoring, telemedicine, tele-counselling, Virtual Doctor, assets hygiene, smart isolation wards, and so on. Some SMEs and key stakeholders think that COVID19 is just a short obstacle in the Smart Cities growth path due to reduced budgets and shifting priorities, however, post COVID-19, the Smart Cities can witness a huge jump in technology investment and deployment to enable city residents better and fear-free life. We are sure that during and after the COVID-19 pandemic, our shifting priorities and focus can only make Smart Cities smarter and better as per the principles of predictive analysis [30].

\section{CONCLUSION :}

The COVID-19 pandemic has changed the day to day activities and the way we were living our life so far to a significant extent. Social distancing, maintaining cleanliness, contactless transactions are now becoming norms. Smart Cities also have been forced to shift their priorities and now Smart Cities are more focusing on building Smart Medical Services such as Telemedicine, Virtual Doctor, powerful Medical Infrastructure, Smart Isolation Wards, dedicated Command Control Centres to effectively tackle any pandemic situation and so on. Due to severe budget cut and prolonged imposed lockdown due COVID-19, Smart Cities are giving lower priority to services such as building Tourism spots, entertainment Parks, Social Gathering events and similar such activities. On the other hand, due to COVID-19 pandemic some benefits are also seen for example due to extended lockdown, many Smart Cities witnessed significant improvement in air quality, the pollution reduced drastically and citizens could breathe fresh air, also many river waters which were polluted from log time due to continuous dumping of waste, seen improvement in the overall quality of water and water start looking very clean. It is also revealed that despite poor economies, Smart Cities are in fact making good progress comparing to other businesses in building Smart Medical facilities since for such activities they have received generous funding support from Governments, NGOs, and Public Private Partnership bodies. Smart Cities are overall fighting well with COVID-19 pandemic and will continue to tackle smartly for any such pandemic in future. Post COVID-19, it is hoped by scientists, researchers, and SMEs that Smart Cities development will not slow down rather it will be accelerated to well cope with any unforeseen situations like COVID-19 Pandemic.

\section{REFERENCES :}

[1] Gade, Dipak. (2019). Introduction to Smart Cities and Selected Literature Review. International Journal of Advance and Innovative Research, 6/2 (VI), 7-15.

[2] Hisham Abusaada \& Abeer Elshater. (2020). COVID-19 Challenge, Information Technologies, and Smart Cities: Considerations for Well-Being. International Journal of Community Well-Being, $3(1), 417-424$.

[3] Lauren M. Andersen, Stella R. Harden, Margaret M. Sugg, Jennifer D. Runkle Taylor E. Lundquist. (2021). Analyzing the spatial determinants of local COVID-19 transmission in the United States. Science of the Total Environment, 754(1), 1-10.

[4] Bo Li, You Peng, He, Mingshu Wang, Tao Feng. (2021). Built environment and early infection of COVID-19 in urban districts: A case study of Huangzhou. Sustainable Cities and Society, 66(1), $1-10$.

[5] Lorenz von Seidlein, Graham Alabaster, Jacqueline Deen, Jakob Knudsen. (2021). Crowding has consequences: Prevention and management of COVID-19 in informal urban settlements. Building and Environment, 188, 1-9.

[6] Nenad N. Petrović, Vlado Dimovski, Judita Peterlin, Maja Meško, Vasja Roblek. (2021). DataDriven Solutions in Smart Cities: The case of COVID-19 Apps. Proceedings of the World Wide Web Conference, 1-9. 
[7] Ibrahim Abaker Targio Hashem, Absalom E. Ezugwu, Mohammed A. Al-Garadi, et al. (2020). A Machine Learning Solution Framework for Combatting COVID-19 in Smart Cities from Multiple Dimensions. medRxiv, 1-68.

[8] Linda Hantrais, Paul Allin, Mihalis Kritikos, Melita Sogomonjan, Prathivadi B. Anand, Sonia Livingstone, Mark Williams \& Martin Innes (2021) COVID-19 and the digital revolution, Contemporary Social Science, 16(2), 256-270.

[9] Mikiharu Arimura, Tran Vinh Ha, Kota Okumura, Takumi Asada (2020). Changes in urban mobility in Sapporo city, Japan due to the COVID-19 emergency declarations. Elsevier, Transportation Research Interdisciplinary Perspectives, 7(9), 1-14.

[10] Franck Fu, Kathleen L. Purvis-Roberts and Branwen Williams (2020). Impact of the COVID-19 Pandemic Lockdown on Air Pollution in 20 Major Cities around the World. MDPI, Atmosphere, 11, 1-18.

[11] Zander S.Venter, Kristin Aunan, Sourangsu Chowdhury, Jos Lelieveld (2021). Air pollution declines during COVID-19 lockdowns mitigate the global health burden, ScienceDirect, Environmental Research, 192, 1-4.

[12] Ayyoob Sharifi, Amir Reza Khavarian-Garmsir (2020). The COVID-19 pandemic: Impacts on cities and major lessons for urban planning, design, and management. Science of the Total Environment, 749, 1-14.

[13] Chunwen Xu, Xilian Luo, Chuck Yu and Shi-Jie Cao. (2020). The 2019-nCoV epidemic control strategies and future challenges of building healthy smart cities. Sage, Indoor and Built Environment, 29(5), 639-644.

[14] Klaus R. Kunzmann (2020). Smart Cities After Covid-19: Ten Narratives. Taylor \& Francis, disP - The Planning Review, 56(2), 20-31.

[15] Shukla, AK. (2020). COVID-19 crisis: Govt uses Smart City infrastructure to keep essential services rolling. Retrieved from https://government.economictimes.indiatimes.com/ on May 30, 2021.

[16] Smart Cities Mission. (2020). Retrieved from http://smartcities.gov.in/ on May 30, 2021.

[17] Smart Cities. (2020). Retrieved from http://mohua.gov.in/cms/smart-cities.php on May 30, 2021.

[18] Siva Soorya MT. (2020). How COVID accelerated smart city development. Retrieved from https://gcn.com/ on May 30, 2021.

[19] Lara Williams. (2020). How COVID-19 is shifting 'smart city' priorities. Retrieved from https://citymonitor.ai/ on May 30, 2021.

[20] Editors Smart City Hub. (2020). Digital twins of smart cities key to understanding impact of COVID-19 measures. Retrieved from http://smartcityhub.com/ on May 30, 2021.

[21] Milly Xiang. (2020). Retrieved from https://www.gartner.com/en/documents/3994916/markettrends-5-smart-city-iot-deployment-trends-to-driv on May 30, 2021.

[22] Daniel G. Costa, João Paulo J. Peixoto. (2020). COVID-19 pandemic: a review of smart cities initiatives to face new outbreaks. IET Smart Cities 2(2), 64-73.

[23] Sara Eltarabily, Dalia Elghezanwy (2020). Post-Pandemic Cities - The Impact of COVID-19 on Cities and Urban Design. Architecture Research, 10(3), 75-84.

[24] Yusra Amir, Sanchari Deb, et al. (2021). Real World Solutions for Smart Cities Transportation to be Pandemic Ready. IEEE Xplore, ICRCICN, 159-164

[25] Zaheer Allam, David S. Jones. (2020). On the Coronavirus (COVID-19) Outbreak and the Smart City Network: Universal Data Sharing Standards Coupled with Artificial Intelligence (AI) to Benefit Urban Health Monitoring and Management, MDPI, Healthcare, 8, 46, 1-9. 
[26] María del Carmen Olmos-Gómez, Mónica Luque-Suárez, Soraya Mohamed-Mohamed and Jesús Manuel Cuevas-Rincón. (2020). Validation of the Smart City as a Sustainable Development Knowledge Tool: The Challenge of Using Technologies in Education during COVID-19, MDPI, Sustainability, 12, 8384, 1-18.

[27] Angeliki Kylili, Nicholas Afxentiou, et al. (2020): The role of Remote Working in smart cities: lessons learnt from COVID-19 pandemic. Taylor \& Francis, Energy Sources, Part A: Recovery, Utilization, and Environmental Effects, 1-17

[28] Mohammad Shorfuzzaman, M., Shamim Hossain, et al. (2020). Towards the sustainable development of smart cities through mass video surveillance: A response to the COVID-19 pandemic Sustainable Cities and Society. Sustainable Cities and Society, 64, 1-11.

[29] Junyi Zhang (2020). Transport policymaking that accounts for COVID-19 and future public health threats: A PASS approach. Transport Policy, 99(1), 405-418.

[30] Aithal, P. S., \& Aithal, S. (2019). New Directions in Scholarly Research-Some Fearless Innovations \& Predictions for 21st Century Research. International Journal of Management, Technology, and Social Sciences (IJMTS), 4(1), 1-19. 